\title{
KELIMPAHAN STOK IKAN ARWANA PAPUA (Scleropages jardinii Saville-Kent, 1892) DI SUNGAI KUMBE, KABUPATEN MERAUKE, PAPUA
}

\section{STOCK ABUNDANCE OF SARATOGA (Scleropages jardinii Saville-Kent, 1892) IN KUMBE RIVER, MERAUKE REGENCY, PAPUA}

\author{
Agus Arifin Sentosa, Arip Rahman dan Hendra Satria \\ Peneliti pada Balai Penelitian Pemulihan dan Konservasi Sumber Daya Ikan-Jatiluhur \\ Teregistrasi I tanggal: 25 Maret 2015; Diterima setelah perbaikan tanggal: 03 Juni 2015; \\ Disetujui terbit tanggal: 05 Juni 2015
}

\begin{abstract}
ABSTRAK
Sungai Kumbe merupakan salah satu habitat utama ikan arwana Papua (Scleropages jardinii Saville-Kent, 1892) di Kabupaten Merauke. Penelitian ini bertujuan untuk mengkaji kelimpahan ikan arwana Papua di Sungai Kumbe, Merauke. Pengambilan data dilakukan pada FebruariMaret dan November-Desember 2013 dengan metode survei melalui percobaan penangkapan serta wawancara langsung dengan nelayan dan pengumpul anakan arwana. Kelimpahan dihitung dengan membagi jumlah induk atau anakan arwana dengan luas area tercakup. Hasil menunjukkan bahwa rata-rata kelimpahan induk dan anakan ikan arwana Papua di Sungai Kumbe adalah sebanyak 1 ekor induk/ha dan 58 ekor anakan/ha. Total anakan yang dapat dimanfaatkan dari perairan Sungai Kumbe agar populasi ikan arwana Papua terjaga kelestariannya adalah sebanyak $321-6.419$ ekor anakan.
\end{abstract}

\section{KATA KUNCI: Arwana Papua, Scleropages jardinii, kelimpahan, Sungai Kumbe, Merauke}

\begin{abstract}
Kumbe River is one of the major habitats of saratoga (Scleropages jardinii Saville-Kent, 1892) in Merauke Regency. This research aims to determine saratoga abundance in Kumbe River, Merauke. The data were collected in February-March and November-December 2013 by survey methods through experimental fishing and direct inverview with fishermen and fries saratoga collectors. The abundance was calculated by the total catch of brood and fries per area. Results show that the abundance of the saratoga broodstocks and fries was estimated about 1 individual/ ha and 58 individual/ha respectively. Total fries saratoga that can be harvested for sustainable saratoga fisheries in Kumbe River ranged of 321-6,419 fries.
\end{abstract}

\section{KEYWORDS: Saratoga, Scleropages jardinii, abundance, Kumbe River, Merauke}

\section{PENDAHULUAN}

Kabupaten Merauke merupakan salah satu bagian wilayah Papua Selatan yang secara geografis berada pada kawasan dataran rendah Trans-Fly (Trans-Fly Coastal Lowlands) dengan karakteristik daerah lahan basah yang luas berupa rawa banjiran dan sungaisungai yang mengalir di wilayah tersebut (Polhemus \& Allen, 2007) serta memiliki tingkat endemisitas organisme perairan yang relatif tinggi (Binur, 2010; Kartikasari et al., 2012). Salah satu sungai besar di wilayah Merauke adalah Sungai Kumbe yang termasuk ke dalam wilayah sungai lintas batas Einlanden-Digul-Bikuma. Sungai tersebut memiliki panjang 300,42 km dengan luas daerah tangkapan air (catchment area) sebesar $3.765,90 \mathrm{~km}^{2}$ (Departemen PU, 2008). Karakteristik daerah aliran sungai (DAS) Kumbe berupa aliran yang lambat dan membentuk rawa banjiran yang didominasi oleh tumbuhan air dengan sekeliling DAS berupa perpaduan antara hutan rawa dan hutan monsoon tropika. Oleh karena itu, Sungai Kumbe telah menjadi salah satu habitat yang ideal bagi ikan-ikan sungai, terutama ikan arwana Papua (Scleropages jardinii Saville-Kent, 1892). Ikan arwana Papua yang merupakan ikan asli dan endemik Papua dengan sentra produksi tangkapan arwana Papua banyak ditemukan di bagian hulu sungai tersebut (Satria, 2013; Sentosa \& Satria, 2013).

Ikan arwana Papua yang memiliki nama umum "saratoga" dan oleh masyarakat setempat sering disebut sebagai "kaloso" mempunyai nilai komersial yang sangat mahal. Status konservasi $S$. jardinii hingga saat ini masih merupakan satwa yang dilindungi berdasarkan pada Peraturan Pemerintah Nomor 7 Tahun 1999, namun juga ditetapkan sebagai satwa buru berdasarkan Keputusan Menteri 
Kehutanan Nomor 209/kpts-II/2001 yang diperbarui oleh Peraturan Menteri Kehutanan Nomor P.12/ Menhut-II/2005 yang intinya adalah pengaturan penangkapan ikan arwana Papua yang dilakukan secara benar misalnya tidak membunuh induk untuk mengambil anakannya dan cara lain yang sejalan dengan prinsip konservasi. Status konservasi $S$. jardinii berbeda dengan kerabatnya yaitu Scleropages formosus yang telah dilindungi secara internasional (Red list Data Book-IUCN dan Appendix I CITES). Konsekuensinya adalah $S$. formosus telah dilarang untuk diperdagangkan kecuali hasil penangkaran, sedangkan $S$. jardinii baru dilindungi secara nasional (Tjakrawidjaja \& Haryono, 2001).

Eksploitasi $S$. jardinii umumnya banyak dilakukan pada anakan atau juwana arwana yang masih berada di mulut induknya. Studi kasus di Sungai Maro, eksploitasi ikan arwana Papua telah berlangsung intensif dan memberikan kontribusi yang cukup besar terhadap pendapatan nelayan dan masyarakat serta pemerintah daerah setempat dan diduga hal tersebut juga terjadi di Sungai Kumbe karena penangkapan ikan arwana Papua merupakan salah satu sumber mata pencaharian utama bagi warga Merauke (Kartamihardja et al., 2013). Satria \& Kartamihardja (2010) selanjutnya menyebutkan bahwa ikan arwana Papua tidak hanya tersebar di beberapa sungai wilayah Kabupaten Merauke saja namun juga di Kabupaten Mappi, Boven Digul dan Asmat. Permasalahan yang dihadapi saat ini adalah kuota eksploitasi masih ditentukan secara keseluruhan dan belum didasarkan pada proporsi potensi kelimpahan stok ikan arwana Papua pada masing-masing kawasan perairan tersebut. Oleh karena itu, pendugaan kelimpahan stok ikan arwana Papua berbasis kawasan perairan perlu dilakukan sebagai dasar dalam penentuan kuota eksploitasi ikan arwana Papua di wilayah Kabupaten Merauke.

Penelitian terkait ikan arwana Papua di Merauke umumnya lebih banyak dilakukan di perairan Sungai Maro seperti hasil penelitian (Astuti \& Satria, 2009; Satria \& Kartamihardja, 2010; Satria, 2012), namun di Sungai Kumbe relatif masih belum banyak dilakukan. Sebagai dukungan terhadap upaya pengelolaan ikan arwana Papua di Sungai Kumbe dilakukan penelitian dengan tujuan untuk mengetahui kelimpahan ikan arwana Papua (Scleropages jardinii) di Sungai Kumbe, Merauke. Hasil penelitian ini diharapkan dapat digunakan sebagai dasar bagi penentuan kuota tangkapan arwana di setiap badan air di Sungai Kumbe.

\section{BAHAN DAN METODE}

Penelitian dilakukan di Sungai Kumbe, Kabupaten Merauke dengan 2 kali survei pada Februari-Maret dan November-Desember 2013 (Gambar 1). Lokasi penangkapan ikan ditentukan di sentra penangkapan arwana yang berada di Sungai Kumbe.

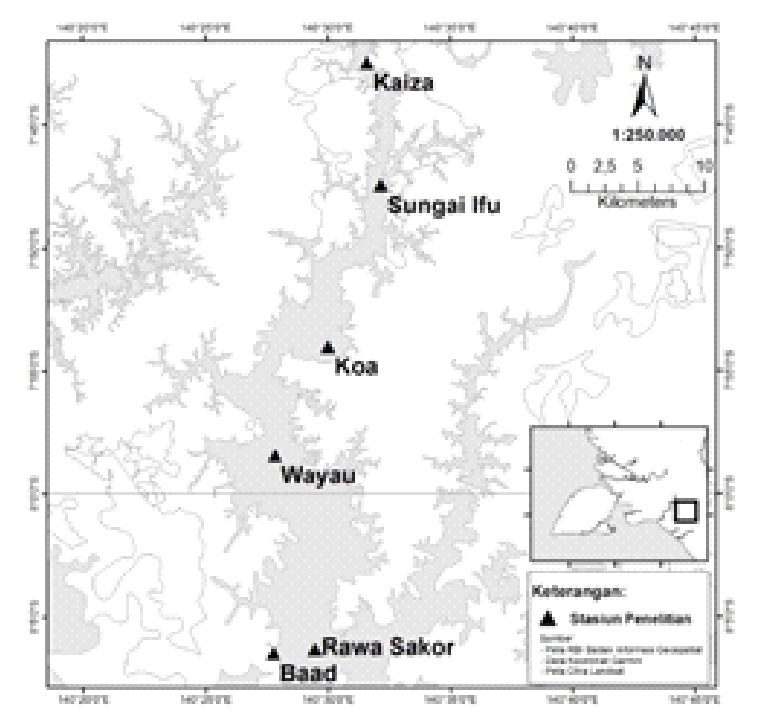

Gambar 1. Lokasi penelitian di Sungai Kumbe, Merauke.

Figure 1. Site research in Kumbe River, Merauke.

Pengumpulan data dilakukan dengan metode survei melalui pelaksanaan percobaan penangkapan ikan dengan jaring insang percobaan berukuran mata jaring 3,5; 4,0 dan 4,5 inci (jaring arwana) disertai wawancara langsung dengan nelayan dan pengumpul anakan arwana. Penangkapan didasarkan pada pertimbangan bahwa lokasi tangkap memiliki karakteristik sebagai habitat asuhan induk arwana 
Papua. Stasiun pengamatan dibagi ke dalam 6 stasiun yaitu: Kaisa, Ifu, Koa, Wayau, Baad dan Sakor. Identifikasi jenis ikan arwana Papua dilakukan berdasarkan Allen (1991) dan Allen et al. (2000).

Penentuan kelimpahan kan arwana dilakukan dengan cara menggiring induk arwana Papua pada suatu area perairan tertentu yang diduga sebagai habitat arwana yang telah dibatasi oleh jaring arwana (net blocking). Penggiringan ikan dilakukan menggunakan galah yang dipukul-pukulkan pada permukaan air sehingga ikan akan bergerak ke arah jaring yang telah dibentangkan. Luasan area tercakup diprediksi berdasarkan panjang tali ris jaring arwana dikalikan jarak penggiringan ikan.

Metode perhitungan dugaan kelimpahan ikan arwana dilakukan dengan modifikasi metode Satria \& Kartamihardja (2010). Pendugaan kelimpahan ikan arwana dilakukan dengan percobaan penangkapan sebanyak dua kali untuk mengetahui jumlah individu per satuan luas pada masing-masing badan air dan berdasarkan wawancara langsung dengan para pengumpul dan nelayan di sentra penangkapan ikan arwana Papua. Rumusan perhitungan populasi kelimpahan ikan arwana Papua dilakukan menggunakan rumus berikut:

Populasi $(P)=N /$

dimana:

$\mathrm{P}=$ kelimpahan populasi (individu/ha)

$\mathrm{N}=$ jumlah individu (individu)

$\mathrm{L}=$ luas yang diamati (ha)

\section{HASIL DAN BAHASAN HASIL}

Kelimpahan induk dan anakan pada masing masing wilayah dan luasan pada sentra produksi di Sungai Kumbe dengan menggunakan metode penggiringan dengan jaring insang percobaan disajikan pada Tabel 1.

Tabel 1. Hasil tangkapan arwana dengan jaring percobaan di Sungai Kumbe

Table 1. Catch of saratoga by using experimental gill net in Kumbe River

\begin{tabular}{|c|c|c|c|c|c|c|c|}
\hline $\begin{array}{l}\text { Daerah/ } \\
\text { Location }\end{array}$ & $\begin{array}{l}\text { Lokasi/ Site } \\
\text { Sampling }\end{array}$ & $\begin{array}{l}\text { Posisi/ GPS } \\
\text { Position }\end{array}$ & $\begin{array}{l}\text { Luas } \\
\text { cakupan/ } \\
\text { Coverage } \\
\text { Area } \\
\text { (ha) }\end{array}$ & $\begin{array}{l}\text { Jumlah } \\
\text { Tangkapan/ } \\
\text { Total Catch } \\
\text { (individu) }\end{array}$ & $\begin{array}{l}\text { Panjang/ } \\
\text { Length of } \\
\text { Fish }(\mathrm{cm})\end{array}$ & $\begin{array}{l}\text { Bobot/ } \\
\text { Weight } \\
\text { of Fish } \\
\text { (gram) }\end{array}$ & $\begin{array}{l}\text { Jumlah } \\
\text { Anakan/ } \\
\text { Total } \\
\text { Fries }\end{array}$ \\
\hline \multirow[t]{6}{*}{ Kaisa } & Mahayulumb & 7०42'40,9" LS & 2 & 2 & 35 & 300 & 42 \\
\hline & & $140^{\circ} 31^{\prime} 52,6^{\prime \prime}$ BT & & & 38 & 400 & 46 \\
\hline & Abahin & $7^{\circ} 37^{\prime} 23,6^{\prime \prime}$ LS & 3 & 4 & 42 & 450 & 52 \\
\hline & & $140^{\circ} 29^{\prime} 47^{\prime \prime} \mathrm{BT}$ & & & 40 & 420 & 48 \\
\hline & & & & & 50 & 650 & 58 \\
\hline & & & & & 55 & 1300 & 65 \\
\hline \multirow[t]{3}{*}{ Sakor } & Sakor & $8^{\circ} 6^{\prime} 27,6 ”$ LS & 3 & 5 & 34 & 330 & 36 \\
\hline & & $140^{\circ} 29^{\prime} 58,6^{\prime \prime} \mathrm{BT}$ & & & 48 & 600 & 61 \\
\hline & & & & & 62 & 1200 & 31 \\
\hline \multirow[t]{2}{*}{ Ifu } & Muara & $7^{\circ} 46^{\prime} 45,3^{\prime \prime}$ LS & 2 & 2 & 45 & 600 & 52 \\
\hline & & $140^{\circ} 32^{\prime} 45,3 " \mathrm{BT}$ & & & 60 & 1400 & 60 \\
\hline \multirow[t]{3}{*}{ Baad } & Sungai Baad & $8^{\circ} 6 ’ 29,4$ " LS & 1 & 2 & 48 & 580 & 44 \\
\hline & & $140^{\circ} 27^{\prime} 46,3^{\prime \prime} \mathrm{BT}$ & & & 60 & 1350 & 46 \\
\hline & & Total & 11 & 15 & & & 641 \\
\hline
\end{tabular}

Satu ekor induk menghasilkan anakan rata-rata sebanyak 42,73 individu H" 43 individu

Kelimpahan induk sebanyak 1,36 individu/ha H" 1 individu/ha

Kelimpahan anakan sebanyak 58,27 individu/ha H" 58 individu/ha

Hasil total tangkapan nelayan di perairan Sungai Kumbe berdasarkan wawancara langsung sebanyak 580 ekor induk dan 29.003 ekor anakan (Gambar 2) sementara pada pengumpul sebanyak 272 induk dan 13.371 ekor anakan (Gambar 3). Hasil tangkapan induk dan produksi anakan ikan arwana yang paling banyak berada pada lokasi Kaisa dengan jumlah induk sebanyak 215 ekor dan anakan sebesar 11.108. Produksi induk dan anakan yang paling sedikit berada pada lokasi Koa dengan jumlah induk sebanyak 19 ekor dan anakan sebanyak 840 ekor. 


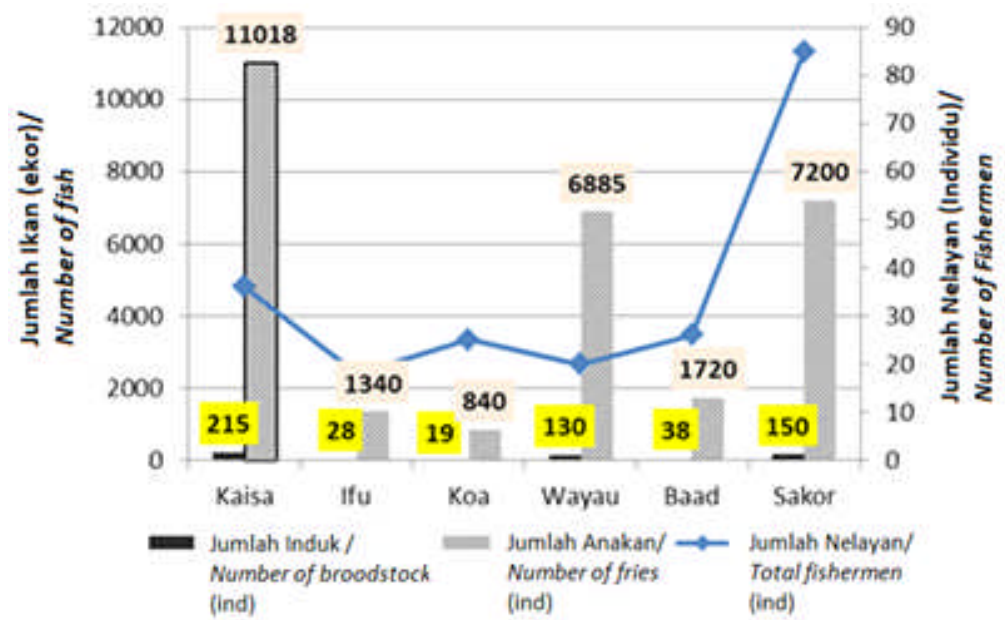

Gambar 2. Hasil tangkapan induk dan anakan S. jardinii di Sungai Kumbe oleh nelayan.

Figure 2. Broodstocks and fries saratoga caught by fishermen in Kumbe River.

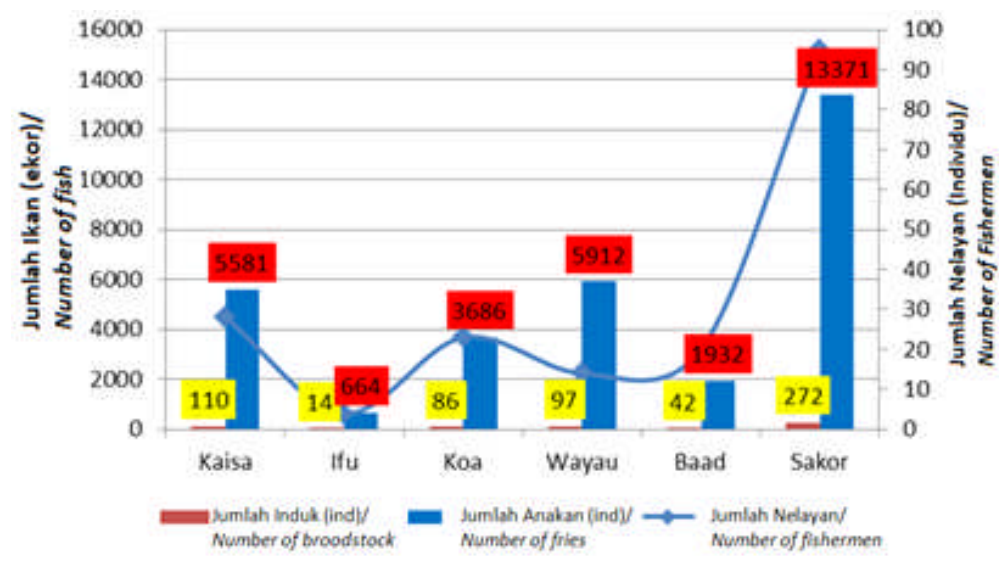

Gambar 3. Hasil tangkapan induk dan anakan S. jardinii di Sungai Kumbe pada pengumpul.

Figure 3. Broodstocks and fries saratoga catch recorded by collector of Kumbe River.

Kegiatan penangkapan yang dilakukan oleh nelayan pada musim tangkapan pada periode 2013 di Sungai Kumbe mencapai puncaknya pada pertengahan November dan berakhir sampai pertengahan Februari. Penangkapan ikan arwana Papua banyak dilakukan pada musim hujan bahkan sampai akhir peralihan antara musim hujan ke musim kemarau (Gambar 4).

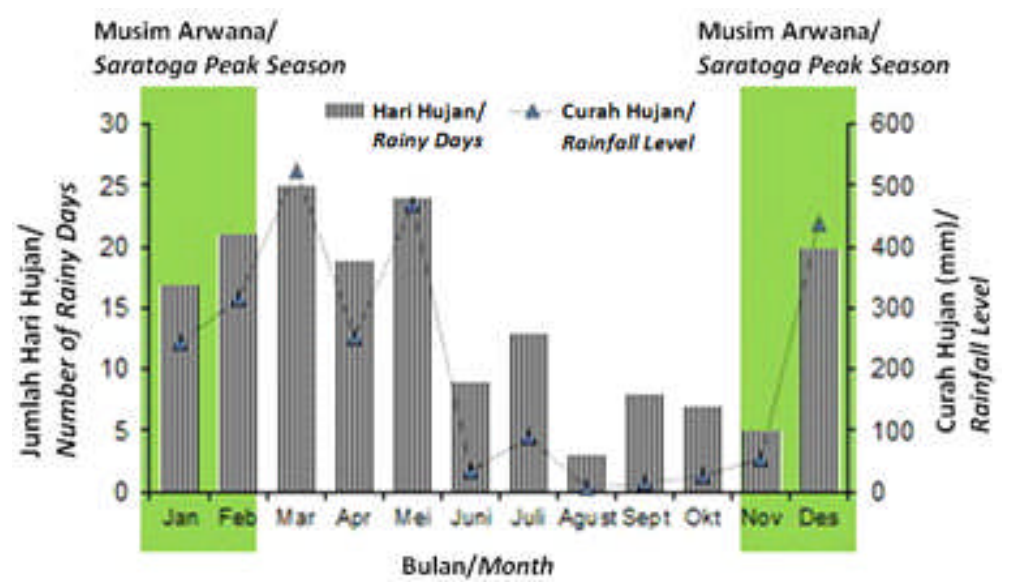

Gambar 4. Pola curah hujan dan musim tangkap S. jardinii di Sungai Kumbe.

Figure 4. Rainfall patterns and the saratoga fishing season in Kumbe River. 
Kelimpahan induk dan anakan ikan arwana Papua juga diduga berdasarkan luas wilayah yang disurvei melalui wawancara langsung dengan nelayan dan pengumpul ikan arwana di sentra-sentra penangkapan sepanjang Sungai Kumbe. Dugaan kelimpahan induk dan anakan arwana Papua berdasarkan wawancara langsung dengan nelayan dan pengumpul ikan disajikan dalam Tabel 2.

Tabel 2. Produksi induk dan anakan ikan arwana Papua di Sungai Kumbe berdasarkan wawancara langsung dengan nelayan dan pengumpul ikan

Table 2. Broodstocks and fries saratoga production in Kumbe River based on direct interview with fishermen and fish collector

\begin{tabular}{|c|c|c|c|c|c|c|}
\hline $\begin{array}{l}\text { Lokasi/ } \\
\text { Location }\end{array}$ & $\begin{array}{l}\text { Luas } \\
\text { cakupan/ } \\
\text { Coverage } \\
\text { Area (ha) }\end{array}$ & $\begin{array}{c}\text { Jumlah } \\
\text { Induk/ } \\
\text { Total } \\
\text { Brood- } \\
\text { stocks (ind) }\end{array}$ & $\begin{array}{c}\text { Jumlah } \\
\text { Anakan/ } \\
\text { Total Fries } \\
\text { (ind) }\end{array}$ & $\begin{array}{l}\text { Anakan } \\
\text { per Induk/ } \\
\text { Fries per } \\
\text { Brood- } \\
\text { stocks }\end{array}$ & $\begin{array}{c}\text { Induk per } \\
\text { ha/ } \\
\text { Brood- } \\
\text { stocks } \\
\text { per ha }\end{array}$ & $\begin{array}{c}\text { Anakan per } \\
\text { ha/ Fries } \\
\text { per ha }\end{array}$ \\
\hline Kaisa & 246 & 251 & 12.795 & 50,98 & 1,02 & 52,01 \\
\hline Ifu & 15 & 14 & 6.62 & 47,29 & 0,93 & 44,13 \\
\hline Koa & 35 & 19 & 8.40 & 44,21 & 0,54 & 24,00 \\
\hline Wayau & 95 & 97 & 5.912 & 60,95 & 1,02 & 62,23 \\
\hline Baad & 34 & 42 & 1.932 & 46,00 & 1,24 & 56,82 \\
\hline Sakor & 194 & 337 & 16.371 & 48,58 & 1,74 & 84,39 \\
\hline Total & 619 & 760 & 38.512 & & & \\
\hline Rerata & 103,17 & 126,67 & $6.418,67$ & 49,67 & 1,08 & 53,93 \\
\hline
\end{tabular}

Estimasi kelimpahan ikan arwana Papua, baik induk dan anakannya dihitung dari seluruh luasan areal di aliran Sungai Kumbe, baik itu berasal dari percobaan penangkapan, pengumpul maupun tangkapan nelayan. Kelimpahan relatif populasi induk dan anakan ikan arwana Papua di Sungai Kumbe disajikan pada Gambar 5. Secara umum, kelimpahan relatif induk dan anakan arwana Papua tampak lebih

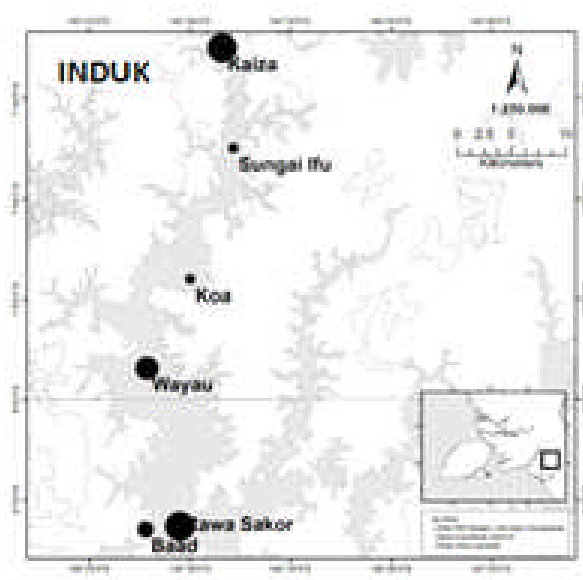

banyak di bagian Sungai Kumbe bagian Kaisa dan Sakor mengingat pada lokasi tersebut relatif jauh dari pemukiman penduduk, sedangkan kelimpahan relatif yang jumlahnya sedikit tercatat di Koa, Wayau dan Baad. Kejadian ini diduga karena lokasinya lebih dekat dengan pemukiman atau kampung penduduk sehingga ikan arwana cenderung menghindari daerah yang banyak terdapat aktivitas manusia.

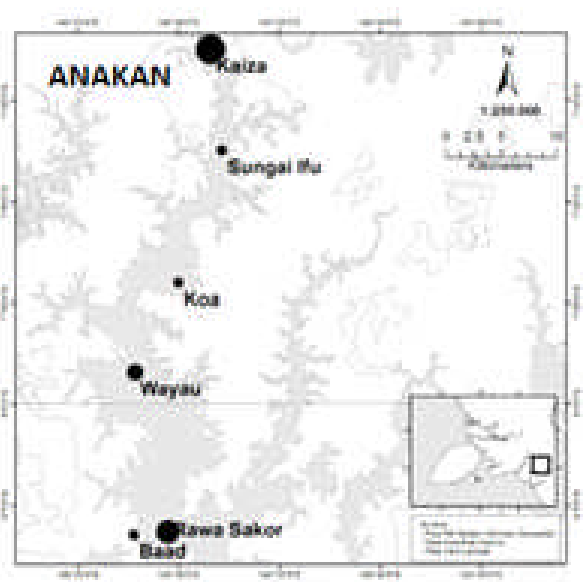

Gambar 5. Kelimpahan relatif induk dan anakan S. jardinii di Sungai Kumbe.

Figure 5. Relative abundance of broodstocks and fries saratoga in Kumbe River.

\section{BAHASAN}

Penangkapan ikan arwana di Sungai Kumbe hampir sama dengan di Sungai Maro dimana puncak musim penangkapan terjadi pada musim hujan
(Kartamihardja et al., 2013; Satria, 2013). Biasanya pada musim hujan, air Sungai Kumbe sudah melimpah dan menggenangi daerah-daerah di sekitarnya menjadi daerah genangan air yang berupa rawa banjiran. Pada rawa-rawa banjiran inilah kegiatan penangkapan ikan 
arwana banyak dilakukan oleh para nelayan. Induk ikan arwana yang sudah memijah pada Oktober tahun sebelumnya kemudian mengasuh anaknya yang berada pada mulutnya kemudian mencari daerah genangan air Sungai Kumbe yang berupa rawa banjiran. Matsumura \& Miliken (1984) menyatakan bahwa di Australia, $S$. jardinii memiliki musim pemijahan pada Oktober dan November dengan jumlah anakan yang dihasilkan berkisar antara 50 90 ekor per induk ikan.

Hasil percobaan dengan jaring insang menunjukkan bahwa rata-rata satu ekor induk menghasilkan sekitar 43 ekor anakan dengan kelimpahan induk sebesar 1 individu/ha dan anakan sekitar 58 anakan/ha. Hal tersebut relatif tidak berbeda dengan dugaan kelimpahan yang diperoleh berdasarkan wawancara langsung dengan pengumpul dan nelayan dimana kelimpahan induk diprediksi sekitar 1 individu/ha dan anakan 54 individu/ha. Kedua pendekatan pendugaan kelimpahan induk dan anakan arwana Papua tidak terlalu berbeda nyata sehingga dapat mendukung satu sama lain. Kondisi tersebut diduga karena hasil tangkapan induk dan anakan memiliki karakteristik yang sama dan hidup pada lokasi yang sama di sepanjang di Sungai Kumbe.

Kelimpahan arwana Papua di Sungai Kumbe berbeda dengan di Sungai Maro, Merauke. Satria \& Kartamihardja (2010) melaporkan bahwa kelimpahan induk dan anakan ikan arwana di Sungai Maro sebesar 1,40 - 1,64 ekor/ha untuk induk dan 73,02 - 86,01 ekor/ha untuk anakan. Rendahnya produksi anakan per ekor induk yang dihasilkan di Sungai Kumbe dibandingkan di Sungai Maro diduga disebabkan adanya tekanan upaya penangkapan ikan yang relatif tinggi di perairan Sungai Kumbe.

Kelimpahan induk dan anakan arwana Papua berdasarkan hasil percobaan penangkapan, wawancara langsung dengan pengumpul dan nelayan kemudian diprediksikan dalam satuan unit luas di seluruh perairan Sungai Kumbe. Besaran populasi induk dan anakan ikan arwana Papua per hektar tersebut akan menjadi pendugaan populasi induk dan anakan yang ada di sentra-sentra produksi. Apablila dilihat dari hasil tangkapan dan produksi anakan ikan arwana dari hasil tangkapan pengumpul dengan nelayan ternyata terdapat sedikit perbedaan di antara lokasi penangkapan. Hal ini disebabkan antara lain: (1) adanya titik lokasi penangkapan yang berbeda; (2) tingginya intensitas penangkapan di titik lokasi tersebut pada periode sebelumnya; (3) keterampilan nelayan masing-masing lokasi tidak sama dalam menangkap induk dan anakan ikan; serta (4) jumlah nelayan sebagai upaya penangkapan ikan tidak sama.
Kegiatan penangkapan $S$. jardinii di Sungai Kumbe secara umum tidak berbeda jauh seperti yang dilakukan di Sungai Maro (Kartamihardja et al., 2013). Ikan yang tertangkap setelah diambil anakannya lalu dilepaskan kembali ke perairan. Namun, sebagai akibat penangkapan dengan jaring insang, banyak ditemukan induk ikan yang mati. Oleh sebab itu, penanganan ikan hasil tangkapan haruslah mendapatkan perhatian yang serius. Kenyataan di lapangan bahwa anakan ikan arwana yang diperoleh dari induknya hanya sebagian kecil saja yang dikembalikan lagi ke perairan sementara sebagian besar anakan ditangkap. Pelepasan kembali anakan ikan arwana karena tidak laku terjual ke pengumpul atau penangkar dimaksudkan agar anakan tersebut dapat tumbuh menjadi rekrutmen populasi ikan selanjutnya. Usaha ini diharapkan akan menjamin kelangsungan hidup anakan ikan arwana Papua untuk mencapai ukuran dewasa atau menjadi induk.

Produksi induk dan anakan Scleropages jardinii yang dihasilkan dari perairan Sungai Kumbe pada 2013 tercatat 760 ekor induk dengan total anakan sebesar 38.512 ekor. Kartamihardja et al. (2013) menyatakan bahwa agar kelestarian sumber daya ikan arwana dapat terjaga perlu pendekatan kehati-hatian dalam eksploitasi anakan ikan arwana. Kuota anakan arwana dari perairan Sungai Kumbe yang dapat dimanfaatkan adalah sebesar $50 \%$ dari total produksi anakan ikan arwana yang dihasilkan. Dengan demikian, maka total anakan yang dapat dimanfaatkan dari perairan Sungai Kumbe berkisar antara $321-6.419$ ekor anakan. Hasil penelitian ini dapat dijadikan basis data untuk menentukan kuota tangkapan ikan arwana Papua di masa datang. Nilai tersebut sangat jauh lebih kecil dari kuota anakan arwana di Sungai Maro sebesar 112.800 ekor (Satria \& Kartamihardja, 2010). Perbedaan tersebut diduga karena potensi anakan arwana di Sungai Maro memang lebih tinggi dibandingkan di Sungai Kumbe dan juga dipengaruhi oleh luasan daerah asuhan berupa rawa banjiran yang relatif lebih luas di Sungai Maro dibandingkan di Sungai Kumbe. Penyebab lain bisa jadi karena tekanan eksploitasi ikan arwana Papua yang semakin meningkat di Merauke sehingga perhitungan kelimpahan dan kuota yang dihasilkan menjadi relatif lebih kecil.

\section{KESIMPULAN}

Produksi induk dan anakan Scleropages jardinii yang dihasilkan dari perairan Sungai Kumbe pada 2013 adalah sebesar 760 ekor induk dengan total anakan sebesar 38.512 ekor. Kelimpahan induk dan anakan ikan arwana Papua di Sungai Kumbe adalah rata-rata sebesar 1 ekor induk/ha dan 58 ekor anakan/ 
ha. Total anakan yang dapat dimanfaatkan dari perairan Sungai Kumbe agar populasi ikan arwana Papua dapat lestari adalah sebesar 321 - 6.419 ekor anakan.

\section{PERSANTUNAN}

Tulisan ini merupakan kontribusi dari kegiatan penelitian "Pendekatan Ekosistem untuk Pengelolaan Populasi Ikan Arwana Papua (Scleropages jardinii) di Sungai Kumbe, Merauke, Papua", Tahun Anggaran 2013 di Balai Penelitian Pemulihan dan Konservasi Sumber Daya lkan. Terima kasih disampaikan kepada seluruh pihak yang telah mendukung terhadap pelaksanaan penelitian, terutama Prof. Dr. Ir. Endi Setiadi Kartamihardja. M.Sc. untuk supervisinya.

\section{DAFTAR PUSTAKA}

Allen, G.R. 1991. Field guide to the freshwater fishes of New Guinea. Christensen Research Institute, Madang - Papua New Guinea. 268 pp.

Allen, G.R., K.G. Hortle \& S.J. Renyaan. 2000. Freshwater fishes of the Timika Region New Guinea. PT Freeport Indonesian Company, Timika. $175 \mathrm{pp}$.

Astuti, L.P. \& H. Satria. 2009. Kondisi perairan pada musim pemijahan ikan Arwana Papua (Scleropages jardinii) di Sungai Maro Bagian Tengah, Kabupaten Merauke. BAWAL. 2 (4). 155161.

Binur, R. 2010. Komposisi jenis ikan air tawar di daerah lahan basah Kaliki, Merauke Papua. J. Iktiologi.Ind. 10 (2): 165-178.

Direktorat Jenderal Sumber Daya Air Departemen Pekerjaan Umum. 2008. Profil Balai Wilayah Sungai Papua. http://www.pu.go.id/satminkal/dit_sda/ profil\%20balai/bws/profilebalaipapua_baru.pdf. Diakses tanggal 23 Februari 2011.

Kartamihardja, E.S., K. Purnomo, D.W.H. Tjahjo \& S. Koeshendrajana. 2013. Pendekatan ekosistem untuk pengelolaan sumberdaya ikan Arwana
Papua, Scleropages jardinii di Sungai Maro, Merauke-Papua. J.Kebijakan.Perik.Ind. 5 (2): 87 96.

Kartikasari, S.N., A.J. Marshall \& B.M. Beehler (eds). 2012. Ekologi Papua. Seri Ekologi Indonesia, Jilid VI. Yayasan Obor Indonesia dan Conservation International, Jakarta. 982 pp.

Matsumura, S. \& T. Miliken. 1984. The Javanese trade in bony tongue and CITES-listed fish. Traffic Bull. $3(4): 42-50$.

Polhemus, D.A. \& G.R. Allen. 2007. Freshwater Biogeography of Papua. In: Marshall, AJ \& B.M. Beehler (eds.). The Ecology of Papua Part I. Periplus Edition, Singapore. p. 207-245.

Satria, H \& E.S. Kartamihardja. 2010. Kelimpahan Stok dan Pengembangan Suaka Ikan Arwana Papua, Scleropages jardinii (Saville-Kent, 1892) di Sungai Maro, Kabupaten Merauke, Provinsi Papua. J.Lit.Perik.Ind. 16 (1): 49-62.

Satria, H. 2012. Pengelolaan sumberdaya ikan arwana Papua (Scleropages jardinii) di perairan Sungai Maro, Merauke-Papua untuk konservasi. In: Suwardjo et al. (eds). Pros. Sem. Nas. Perik. 2012. Pusat Penelitian dan Pengabdian Masyarakat (P3M). Sekolah Tinggi Perikanan, Jakarta: $165-174$.

Satria, H. 2013. Karakteristik habitat ikan arwana Papua (Scleropages jardinii) di Sungai Kumbe Kabupaten Merauke - Papua. In: Isnansetyo, A. et al., (eds). Pros. Sem. Nas. Tahunan $X$ Hasil Penelitian Perikanan dan Kelautan Tahun 2013 Jilid II: Manajemen Sumberdaya Perikanan. Jurusan Perikanan dan Kelautan Fakultas Pertanian Universitas Gadjah Mada. p. MB-09: 115.

Sentosa, A.A. \& H. Satria, 2013. Komposisi ikan hasil tangkapan jaring insang di bagian hulu Sungai Kumbe, Kabupaten Merauke, Papua. In: Isnansetyo, A. et al., (eds). Pros. Sem. Nas. Tahunan X Hasil Penelitian Perikanan dan Kelautan Tahun 2013 Jilid II: Manajemen 
Sumberdaya Perikanan. Jurusan Perikanan dan Kelautan Fakultas Pertanian Universitas Gadjah Mada. p. MD-11.: 1 - 7 .
Tjakrawidjaja, A.H \& Haryono. 2001. Studi populasi ikan kaloso (Scleropages jardinii) di Rawa Pomo, Kecamatan Citak Mitak, Kabupaten Merauke Papua. Berita.Biol. 5 (4): 357-364. 